\title{
Symptoms and transmission of intestinal cryptosporidiosis
}

\author{
M Egger, D Mäusezahl, P Odermatt, H-P Marti, M Tanner
}

\begin{abstract}
Cryptosporidium spp are a cause of diarrhoea in toddlers. Symptoms and routes of transmission were investigated in a prospective casecontrol study in the city and surroundings of Basel, Switzerland. Twenty one $(4.6 \%)$ out of 455 children with diarrhoea who attended paediatric and general practices from June to September 1988 were positive for cryptosporidium. The mothers of each case, of two controls with diarrhoea of another origin, and of two healthy controls were interviewed with a standardised questionnaire. In comparison with controls with diarrhoea of another origin, respiratory symptoms were significantly more frequent in children with cryptosporidiosis: eight of $19(42 \%)$ compared with five of 38 (13\%). In comparison with healthy controls, preceding contact with a person suffering from diarrhoea was associated with the greatest relative risk for cryptosporidiosis, followed by travel in a Mediterranean country. Transient cryptosporidial infection of the respiratory tract may be common in immunocompetent children. In the area investigated person to person transmission may account for most cases.
\end{abstract}

Cryptosporidium spp, a coccidian parasite first described in 1907,1 has only recently been recognised as a relatively frequent cause of diarrhoea in children. In Switzerland $5.5 \%$ of children with diarrhoea identified by a laboratory based survey were found to be positive for oocysts of Cryptosporidium spp. ${ }^{2}$ In immunocompetent children the disease is usually self limiting, but it may be severe in immunodeficient patients. ${ }^{2}{ }^{3}$ Cryptosporidiosis has been considered as an 'emerging zoonosis' with reservoirs in cattle and domestic animals, and in the faecally contaminated environment. ${ }^{4}$ Other ways of transmission have been reported, including person to person transmission, ${ }^{5}$ and transmission by contaminated food and waterfor example, when travelling. ${ }^{6}$ Outbreaks in daycare centres and families have been documented. ${ }^{7}$

In order to elucidate symptoms and major routes of transmission associated with this parasitosis in an urban and periurban area of Switzerland, the present case-control study was undertaken.

\section{Patients and methods}

Eleven paediatric and general practices in the city of Basel, Switzerland, and 29 practices in the periurban areas around Basel participated in the study. All children up to the age of 16 who presented with diarrhoea at one of the practices during the period June to September 1988 were included in the study. At least two stool specimens from each child were subsequently examined for oocysts of Cryptosporidium spp using the auramine fluorescence staining technique. ${ }^{2}$ In doubtful cases the stool samples were concentrated using the method according to Ritchie, ${ }^{8}$ and the modified Ziehl-Neelson staining technique was used for the sediment. ${ }^{9}$ All oocyst positive stools were examined for rotavirus and adenovirus using latex agglutination (Diarlex, Orion Diagnostica); for salmonella, shigella, yersinia, campylobacter using selective mediums (Bio Mérieux); and for Giardia lamblia and Entamoeba histolytica (MIFconcentration method ${ }^{10}$ ).

Cases were defined as all patients with diarrhoea with at least one oocyst positive stool and no concomitant infection with another agent.

Diarrhoea controls: for each case, two patients with diarrhoea who were negative for oocysts were randomly selected and frequency matched to cases for age. Age strata were as follows: $<2$ years, 2-4 years, $4-7$ years, and $>7$ years.

Also for each case, two healthy control children were randomly selected from the children who had attended the study practices for various reasons but not for diarrhoea. They were selected as soon as diagnosis in the corresponding case had been made, and were matched to cases for sex and age within the same strata.

\section{STANDARDISED INTERVIEW}

Mothers of cases of cryptosporidiosis, of healthy controls, and of controls with other causes of diarrhoea were interviewed by two of us (DM and PO) using an identical questionnaire. Interviews in the case and in the healthy controls were carried out by the same person just after diagnosis of the case. The questionnaire consisted of 122 mainly closed questions. It had been tested for ambiguity and interobserver variation in a pilot study. Information was sought relating to personal medical history, living conditions, behavioural patterns, animal contact (including pets), contacts with persons suffering from diarrhoea, consumption of food and drink (quantity and type), and travelling. The questions covered the time period 10 days before the onset of disease in patients and 10 days preceding the interview in healthy controls. In children with cryptosporidiosis and controls with diarrhoea additional questions relating to symptoms and severity of disease were included. 
STATISTICAL ANALYSIS

Student's unpaired, two tailed $t$ tests and $\chi^{2}$ tests with continuity correction were used for the comparison of groups. Fisher's exact test was used if the smallest expected value was less than five. Two sided Fisher's exact tests were calculated taking the total probability of tables, in either tail, which were at least as small as the one observed. " A matched case-control analysis was performed. ${ }^{12}$ Regression for conditional likelihood $^{13}$ was used for the calculation of univariate relative risk estimates, $95 \%$ confidence intervals, and likelihood ratio $\left(\chi^{2}\right)$ statistics (program PECAN, version $2 \cdot 1^{14}$ ).

\section{Results}

During the study period 455 children with diarrhoea were identified. Twenty one $(4 \cdot 6 \%)$ were positive for oocysts of Cryptosporidium spp (June $2 \cdot 5 \%$, July $0 \%$, August $6 \cdot 6 \%$, September $6 \cdot 8 \%)$. Two children were excluded from analysis because they were concomitantly infected with rotavirus or salmonella. Therefore, in the analysis 19 children with cryptosporidiosis were compared with 38 healthy controls and 38 controls suffering from diarrhoea of another origin. All study children were considered immunocompetent by their physician.

Three cases of cryptosporidiosis were part of a family outbreak. Another child had visited a kindergarten where nine out of 22 children and the two teachers were suffering from diarrhoea. These outbreaks will be reported elsewhere. The remaining 15 cryptosporidiosis cases could not be traced to an outbreak.

Table 1 shows the clinical characteristics of study patients. Age and sex were similar among cases and controls. Cryptosporidiosis cases more often lived in the city of Basel than in the periurban areas. Living conditions were not more crowded than those of control patients as judged by the number of persons per room

Table 2 shows data relating to symptoms in cryptosporidiosis cases and age matched oocyst negative controls with diarrhoea. Fever was milder in cryptosporidiosis patients. Duration of diarrhoea, frequency of gastrointestinal symptoms, and stool characteristics were very similar in children with cryptosporidiosis and controls with diarrhoea. However, cough was noted in eight of 19 cryptosporidiosis cases (42\%) compared with only five of 38 controls (13\%) with diarrhoea $(p=0 \cdot 02)$. The relative risk for cough was 3.2 with a $95 \%$ confidence interval of $1 \cdot 2$ to $8 \cdot 4$

Table 3 shows frequencies of exposure to possible sources of infection in cases of crypto-

Table 1 Characteristics of children with cryptosporidiosis, controls with diarrhoea of another origin, and healthy controls

\begin{tabular}{lccc}
\hline & $\begin{array}{l}\text { Children with } \\
\text { cryptosporidiosis } \\
(n=19)\end{array}$ & $\begin{array}{l}\text { Controls with diarrhoea } \\
\text { of another origin } \\
(n=38)\end{array}$ & $\begin{array}{l}\text { Healthy controls } \\
(n=38)\end{array}$ \\
\hline $\begin{array}{l}\text { Mean (SD) age (years) } \\
\text { Sex (M:F) }\end{array}$ & $5 \cdot 4(4)$ & $4 \cdot 7(3)$ & $5 \cdot 4(4)$ \\
$\begin{array}{l}\text { No (\%) at place of residence:* } \\
\text { Urban }\end{array}$ & $14: 5$ & $23: 15$ & $28: 10$ \\
$\begin{array}{l}\text { Periurban } \\
\text { Mean (SD) No of persons/room }\end{array}$ & $\begin{array}{c}7(37) \dagger \\
12(63)\end{array}$ & $\begin{array}{c}7(18) \\
(82)\end{array}$ & $53(13) \dagger$ \\
\end{tabular}

*Urban: Basel county city (Kanton Basel-Stadt); periurban: Basel county country (Kanton Basel-Land)

Basel-Land).
$t \mathrm{p}=08$ for comparison healthy controls compared with cryptosporidiosis cases (two sided Fisher's $\mathrm{tp}=0.08$ for
exact test).
Table 2 Severity of disease and symptoms in children with cryptosporidiosis and controls with diarrhoea of another origin

\begin{tabular}{|c|c|c|c|}
\hline & $\begin{array}{l}\text { Children with } \\
\text { cryptosporidiosis } \\
(n=19)\end{array}$ & $\begin{array}{l}\text { Controls with } \\
\text { diarrhoea of } \\
\text { another } \\
\text { origin } \\
(n=38)\end{array}$ & $p$ Value $^{*}$ \\
\hline $\begin{array}{l}\text { Mean (SD) duration } \\
\text { of diarrhoea } \\
\text { (days) }\end{array}$ & $9 \cdot 8(10)$ & $13 \cdot 1 \quad(16)$ & \\
\hline $\begin{array}{l}\text { No (\%) with fever } \\
\left(\geqslant 37.5^{\circ} \mathrm{C}\right) \\
\text { Mean (SD) highest }\end{array}$ & $11(57)$ & $23(60)$ & 0.92 \\
\hline $\begin{array}{l}\text { temperature } \\
\text { measured }\left({ }^{\circ} \mathrm{C}\right) \\
\text { No (\%) with: }\end{array}$ & $38.0(0 \cdot 8)$ & $38.6(1.0)$ & 0.06 \\
\hline $\begin{array}{l}\text { Abdominal pain } \\
\text { Abdominal }\end{array}$ & $13(68)$ & $28(74)$ & 0.92 \\
\hline $\begin{array}{l}\text { cramps } \\
\text { Vomiting } \\
\text { Meteorism }\end{array}$ & $\begin{array}{r}7(37) \\
12(63) \\
6(31)\end{array}$ & $\begin{array}{r}15(39) \\
19(50) \\
9(24)\end{array}$ & $\begin{array}{l}0.92 \\
0.51 \\
0.75\end{array}$ \\
\hline $\begin{array}{l}\text { Stools: } \\
\text { Watery } \\
\text { Bloody } \\
\text { Slimy } \\
\text { Cough }\end{array}$ & $\begin{aligned} 13 & (69) \\
1 & (5) \\
5 & (26) \\
8 & (42)\end{aligned}$ & $\begin{array}{r}17(46) \\
4(10) \\
17(44) \\
5(13)\end{array}$ & $\begin{array}{l}0.23 \\
0.02 \dagger\end{array}$ \\
\hline
\end{tabular}

*Student's $t$ tests and $\chi^{2}$ tests with continuity correction except for $t=$ two sided Fisher's exact test.

sporidiosis and healthy controls. Preceding contact with a person suffering from diarrhoea was mentioned in 10 of 19 cases $(52 \%)$ but only in one of 38 controls (3\%). Attendance at a kindergarten was also more frequent in cases. On the other hand, frequency of contact with any animal was not different in the two groups. There is evidence that preceding contact with a cat or dog, however, that failed to thrive was more frequent in children with cryptosporidiosis. Use of dummies and preceding holidays in the Mediterranean region (Spain, Southern Italy, Turkey, and Israel) were also more frequent among children with cryptosporidiosis. Consumption of various food items including salad vegetables was similar in the two groups except for unpasteurised milk, which was consumed by five of the 19 cases $(26 \%)$ compared with three of the 38 controls (8\%). Relative risk estimates and $95 \%$ confidence intervals, calculated by conditional logistic regression, are also shown. Contact with a person suffering from diarrhoea was associated with the greatest relative risk, followed by travel in a Mediterranean country. However, the importance of an exposure should not only be judged from the relative risk. The attributable risk takes the frequency of an exposure in the population into account and indicates the proportion of cases which may be attributable to an exposure. ${ }^{15}$ From this point of view person contact again ranked first (attributable risk: $33 \%$ ), followed by animal contact $(26 \%)$, consumption of unpasteurised milk (20\%), and travelling to Mediterranean countries $(16 \%)$.

\section{Discussion}

Cryptosporidiosis is a cause of acute, self limiting diarrhoea in immunocompetent toddlers but may lead to severe, life threatening diarrhoea if immunodeficiency is present. ${ }^{3}$ Patients with AIDS and patients treated with immunosuppressive drugs are at risk. In the absence of an effective treatment, prevention of cryptosporidial infection is essential. For that purpose the importance of different possible ways of transmission should be known. Whereas it is seldom possible to establish the chain of infection in 
Table 3 Exposure frequencies among children with cryptosporidiosis and healthy controls and univariate relative risk estimates with $95 \%$ confidence intervals from logistic regression analysis. Results are numbers (\%)

\begin{tabular}{|c|c|c|c|c|c|}
\hline & $\begin{array}{l}\text { Children with } \\
\text { cryptosporidiosis } \\
(n=19)\end{array}$ & $\begin{array}{l}\text { Healthy } \\
\text { controls } \\
(n=38)\end{array}$ & $p$ Value & $\begin{array}{l}\text { Relative } \\
\text { risk }\end{array}$ & $\begin{array}{l}95 \% \\
\text { Confidence } \\
\text { interval }\end{array}$ \\
\hline $\begin{array}{l}\text { Contact with person suffering from diarrhoea } \\
\text { Visited kindergarten } \\
\text { Animal contact: }\end{array}$ & $\begin{array}{r}10(52) \\
4(21)\end{array}$ & $\begin{array}{l}1(3) \\
2(5)\end{array}$ & $\begin{array}{l}<\cdot 0001 \dagger \\
0.08 \dagger\end{array}$ & $\begin{array}{r}20 \cdot 0 \\
4 \cdot 0\end{array}$ & $\begin{array}{l}2.5 \text { to } 156 \\
0.73 \text { to } 22\end{array}$ \\
\hline $\begin{array}{l}\text { Any } \\
\text { Dog } \\
\text { Cat } \\
\text { Calf }\end{array}$ & $\begin{array}{l}16(84) \\
11(58) \\
11(58) \\
1(5)\end{array}$ & $\begin{array}{l}31(82) \\
19(50) \\
19(50) \\
1(3)\end{array}$ & $\begin{array}{l}0.90 \\
0 \cdot 78 \\
0 \cdot 78 \\
0 \cdot 79\end{array}$ & 二 & \\
\hline $\begin{array}{l}\text { Dog, skinny } \\
\text { Cat, skinny } \\
\text { Dummy } \\
\text { Travelled in Mediterranean country } \\
\text { Consumed untreated milk }\end{array}$ & $\begin{aligned} & 4(21) \\
& 4(21) \\
& 10(53) \\
& 5(26) \\
& 5(26)\end{aligned}$ & $\begin{aligned} 2 & (5) \\
2 & (5) \\
12 & (31) \\
2 & (5) \\
3 & (8)\end{aligned}$ & $\begin{array}{l}0.08 \dagger \\
0.08 \dagger \\
0.21 \\
0.03 \dagger \\
0.10 \dagger\end{array}$ & $\begin{array}{l}4 \cdot 0 \\
4 \cdot 0 \\
3 \cdot 2 \\
5 \cdot 0 \\
4 \cdot 3\end{array}$ & $\begin{array}{l}0.73 \text { to } 22 \\
0.73 \text { to } 22 \\
0.80 \text { to } 12 \\
1 \cdot 1 \text { to } 25 \\
0.85 \text { to } 22\end{array}$ \\
\hline
\end{tabular}

${ }^{*} \chi^{2}$ tests with continuity correction except for $\dagger=$ two sided Fisher's exact test.

individual cases, case-control studies can identify the exposures which are associated with the disease.

In this study contact with a person suffering from diarrhoea was the most important risk factor for intestinal cryptosporidiosis in children living in an urban and periurban area in Switzerland. A weak association with cats and dogs who were failing to thrive but not with healthy animals was evident. These results indicate that most cases were infected by person to person transmission. Consumption of untreated milk may also be a risk factor and may be an important source of infection in rural areas. Pasteurisation destroys infective oocysts. ${ }^{16}$ Our results also suggest that Cryptosporidium spp may be a cause of traveller's diarrhoea. ${ }^{6}$ Dummies were also associated with the disease and because of their widespread use they and other fomites may often play an important part in the chain of infection. This finding is not surprising in the light of the high degree of environmental resistance of cryptosporidial oocysts. ${ }^{17}$

Concomitant bronchitis was significantly more frequent in cases of cryptosporidiosis than in age matched children suffering from diarrhoea of different origin. Respiratory cryptosporidiosis is an established complication in AIDS patients. ${ }^{18}$ Harari et al, however, also detected oocysts in the tracheal fluid of an immunocompetent child, aged 8 months, who was suffering from severe bronchitis and gastroenteritis. ${ }^{19}$ In addition, respiratory symptoms were mentioned in two case series from Bangladesh and Brazil where six out of $18(33 \%)$ and five out of nine (55\%) immunocompetent cases were affected with bronchitis. ${ }^{20} 21$ Our results suggest that transitory cryptosporidial infection of the respiratory tract may be common in immunocompetent children. This infection may be acquired by inhaled oocysts or by small aspirates of vomit that contains oocysts. $^{22}$ Further studies are still needed in order to investigate the importance of respiratory infections with Cryptosporidium spp in immunocompetent children.

Cats and dogs who fail to thrive may well be suffering from chronic cryptosporidiosis ${ }^{23}$ and transmit the disease to humans and especially children. ${ }^{24}$ Despite this fact, our findings suggest that person to person transmission is the major route of infection in our urban and periurban setting. The findings of this controlled study therefore support the hypothesis put forward by Casemore and Jackson, that 'cryptosporidiosis should not be regarded primarily as a zoonosis'.25

We thank all the paediatricians, general practitioners, practice assistants, and parents whose collaboration made this study possible. We are grateful to $\mathrm{Dr} X \mathrm{X}$ Mai for advice relating to the auramine stains and to Professor Dr P G Smith for statistical advice. We should also like to thank Professor Dr M Gasser for kindly performing the microbiological stool examinations and Mrs E Escher and Mrs B Calmbach for excellent laboratory work.

1 Tyzzer EE. A sporozoan found in the peptic glands of the common mouse. Proc Soc Exp Biol Med 1907;5:12-3

2 Mai Nguyen X. Cryptosporidial diarrhoea in children. Infection 1987; 15:444-6.

3 Demonstration at the Royal College of Physicians of London. Immunodeficiency and cryptosporidiosis. $\mathrm{Br} \mathrm{Med} \mathcal{f} 1980$ 281:1123-7.

4 Schultz MG. Emerging zoonoses. [Editorial.] N Engl f Med 1983;308:1285-6.

5 Baxby D, Hart CA, Taylor C. Human cryptosporidiosis: a possible case of hospital cross infection. $\mathrm{Br}$ Med $\mathrm{J} 1983$ 287:1760-61.

6 Jokipii L, Pohjola S, Jokipii AMM. Cryptosporidiosis associated with travelling and giardiasis. Gastroenterology 1985 89:838-42.

7 Wolfson JS, Richter JM, Waldron MA, Weber DJ, McCarthy DM, Hopkins CC. Cryptosporidiosis in immunocompetent patients. $N$ Engl f Med 1985;312 1278-82.

8 Ritchie LS. An ether sedimentation technique for routine stool examinations. Bulletin of the United States Army Medical Department 1948;8:326.

9 Henriksen SA, Pohlenz JFL. Staining of cryptosporidia by a modified Ziehl-Neelson technique. Acta Vet Scand 1981; 22:594-6.

10 Sapero JJ, Lawless DK. 'MIF' stain-preservation technic for identification of intestinal protozoa. American fournal of Tropical Medicine 1953;2:613-9.

11 Armitage P, Berry G. Statistical methods in medical research. 2nd Ed. Oxford: Blackwell Scientific Publications, 1987: 132 .

12 Schlesselmann J. Case-control studies. Design, conduct, analysis. New York: Oxford University Press, 1982:213-5.

13 Breslow NE, Day NE. Statistical methods in cancer research. Vol 1. Lyon: IARC, 1980:249-79.
Vol

14 Lubin JH. A computer program for the analysis of matched case-control studies. Computer and Biomedical Research case-control studies $1981 ; 14: 138-43$.

15 Schlesselmann J. Case-control studies. Design, conduct analysis. New York: Oxford University Press, 1982:43-5

16 Anderson BC. Moist heat inactivation of cryptosporidium sp. Am ₹ Public Health 1985;75:1433-4.

17 Campbell I, Tzipori AS, Hutchinson G, Angus KW. Effect of disinfectants on survival of cryptosporidium oocysts. Vet $\operatorname{Rec} 1982 ; 111: 414-5$.

18 Brady EM, Margolis ML, Korzeniowski OM. Pulmonary cryptosporidiosis in acquired immunodeficiency syndrome AIDS. ҰAMA 1984;252:89-90.

19 Harari MD, West B, Dwyer B. Cryptosporidium as a cause of laryngotracheitis in an infant. Lancet 1986;i:1207.

20 Shahid NS, Rahman AS, Anderson BC, Mata LJ, Sanyal SC. Cryptosporidiosis in Bangladesh. Br Med $\mathcal{f}$ 1985;290: 114-5.

21 Weikel CS, Johnston LI, De Sousa MA, Guerrant RL. Cryptosporidiosis in northeastern Brazil: association with Cryptosporidiosis in northeastern Brazil: associt
sporadic diarrhea. $\mathcal{F}$ Inf Dis 1985;151:963-5.

22 Casemore DP, Jessop EG, Douce D, Jackson FB. Cryptosporidium plus campylobacter: an outbreak in a periurban sporidium plus campylobacter: an outbreak in a periurban
population. Fournal of Hygiene (Cambridge) 1986;96:
95-105.

23 Bennett M, Baxby D, Blundell N, Gaskell CJ, Hart CA, Kelly DF. Cryptosporidiosis in the domestic cat. Vet Rec 1985;116:73-4.

24 Koch KL, Shankey V, Weinstein GS, et al. Cryptosporidiosis in a patient with hemophilia, common variable hypogammaglobulinemia, and the acquired immunodeficiency syndrome. Ann Intern Med 1983;99:337-40.

25 Casemore DP, Jackson FB. Hypothesis: cryptosporidiosis in human beings is not primarily a zoonosis. F Infect 1984; 9:153-6. 